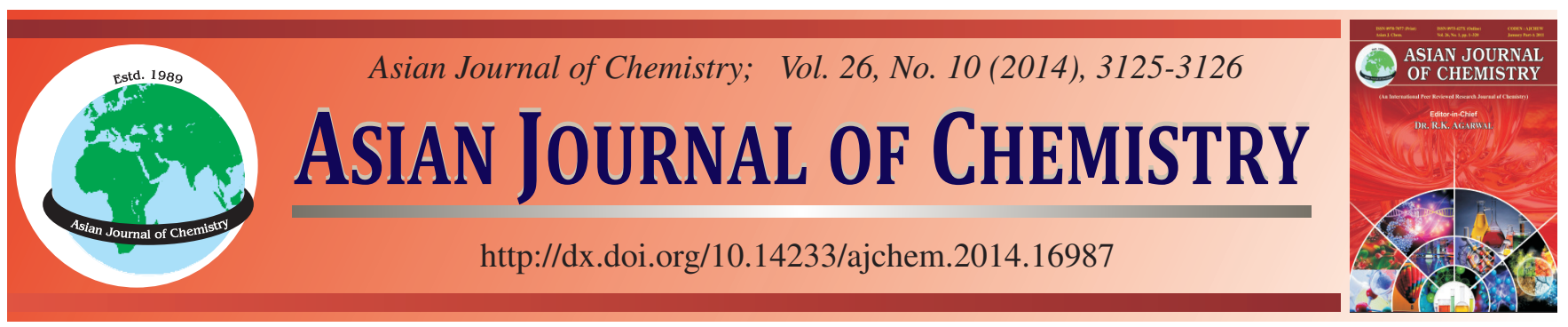

NOTE

\title{
Hydrothermal Synthesis and Crystal Structure of Novel Mn(II) Coordination Polymer Based on 4,4'-Bis(imidazolyl)biphenyl and Trimesic Acid
}

\author{
Guanglong Zou ${ }^{1, *}$, Xuelin Wang ${ }^{2}$, Tingting $^{1}{ }^{1}, Z_{\text {hiqing Fang }}{ }^{1}$ and Bing Xie ${ }^{1, *}$
}

${ }^{1}$ School of Chemistry and Enviromental Science, Guizhou Minzu Univeristy, Guiyang 550025, P.R. China

${ }^{2}$ School of Science, Guizhou Minzu University, Guiyang 550025, P.R. China

*Corresponding authors: E-mail: scesgzmu@126.com

\begin{abstract}
In this paper, a new $\mathrm{Mn}(\mathrm{II})$ coordination polymer with 4,4'-bis(imidazolyl)biphenyl (bib) and trimesic acid ( $\mathrm{H}_{3}$ bct) has been has been prepared by hydrothermal synthesis and characterized by single-crystal X-ray diffraction, IR and EA. Complex, [Mn(Hbta)(bib) $]_{\mathrm{n}}$ (1), is monoclinic, space group $\mathrm{P} 2_{1} / \mathrm{c}$ with $\mathrm{a}=9.380(5), \mathrm{b}=10.226(5), \mathrm{c}=12.590(5) \AA, \beta=86.079(5)^{\circ}, \mathrm{V}=1169.3(10) \AA^{3}, \mathrm{Z}=2, \mathrm{M}_{\mathrm{r}}=549.39$, $\mathrm{Dc}=1.560 \mathrm{~g} / \mathrm{cm}^{3}$ and $\mathrm{F}(000)=562$. The final refinement gave $\mathrm{R}=0.0333$ and $\mathrm{wR}=0.0875$ for 4708 reflections with $\mathrm{I}>2 \sigma(\mathrm{I})$. X-ray diffraction analysis reveals that the complex 1 displays a two-dimensional layer structure.
\end{abstract}

Keywords: Hydrothermal synthesis, Crystal structure, Mn(II) coordination polymer.

Due to the intriguing variety of architecture and potential applications in luminescence, gas storage, molecular magnetism and ion exchange, the construction of metal-organic frameworks (MOFs) have attracted widespread interest in recent years ${ }^{1-4}$. Carboxylate ligands have been employed most often in the design and synthesis for metal-organic frameworks because of their versatile linking capability in virtue of both covalent bonding and supramolecular interaction ${ }^{5-8}$. In the meantime, imidazole-containing ligands, in particular, have proven to be good candidates for the construction of novel metalorganic frameworks due to their flexible and diverse coordination modes ${ }^{9-11}$.

Based on above mention, we used the 4,4'-bis(imidazolyl) biphenyl and trimesic acid to construct a new Mn(II) coordination polymer with $2 \mathrm{D} s q l$ topological net.

All reagents and solvents employed were commercially available and used without further purification. Elemental analysis was carried out on a Carlo Erba 1106 full-automatic trace organic elemental analyzer. FT-IR spectra were recorded with a Bruker Equinox 55 FT-IR spectrometer as a dry $\mathrm{KBr}$ pellet in the $4000-400 \mathrm{~cm}^{-1}$ range.

Synthesis

Preparation of $[\mathbf{M n}(\mathbf{H b t a})(\mathbf{b i b})]_{\mathbf{n}}$ : The mixtures of $\mathrm{MnCl}_{2} \cdot 4 \mathrm{H}_{2} \mathrm{O}(0.099 \mathrm{~g}, 0.5 \mathrm{mmol})$, trimesic acid $\left(\mathrm{H}_{3} \mathrm{btc}\right)(0.105$ g, $0.5 \mathrm{mmol}$ ), 4,4'-bis(imidazolyl)biphenyl (bib) (0.143 g, 0.5 $\mathrm{mmol})$ and $\mathrm{H}_{2} \mathrm{O}(12 \mathrm{~mL})$ were sealed in a $25 \mathrm{~mL}$ Teflon-lined stainless steel vessel. The mixtures were heated at $140{ }^{\circ} \mathrm{C}$ for $72 \mathrm{~h}$ and then cooled to room temperature. The colorless block crystals were obtained and washed with alcohol for several times (Yield: $38 \%$ based on $\mathrm{Mn}$ ). Anal. calcd. for $\mathrm{C}_{27} \mathrm{H}_{18} \mathrm{~N}_{4} \mathrm{O}_{6} \mathrm{Mn}$ : C, 59.03; H, 3.30. N, 10.20. Found: C, 59.05; H, 3.31; N, 10.18. IR/cm ${ }^{-1}(\mathrm{KBr}): 1682 \mathrm{~s}, 1633 \mathrm{~s}, 1574$ s, 1419 m, 1302 m, 1237 m, 1174 m, 1030 m, 955 m, $831 \mathrm{~m}$.

X-ray crystallography: Single crystal X-ray diffraction analyses of complex 1 was carried out on a Bruker SMART APEXII CCD diffractometer equipped with a graphite monochromated $\mathrm{MoK}_{\alpha}$ radiation $(\lambda=0.71073 \AA$ ) by using a $\omega$-scan mode. Empirical absorption correction was applied using the SADABS programs ${ }^{12}$. All the structures were solved by direct methods and refined by full-matrix least-squares methods on $\mathrm{F}^{2}$ using the program SHEXL $97^{13}$. All non-hydrogen atoms were refined anisotropically. The hydrogen atoms were located by geometrically calculations and their positions and thermal parameters were fixed during the structure refinement. Selected bond and angle parameters are listed in Table-1.

[Mn(Hbta)(bib) $]_{\mathbf{n}}$ : The X-ray crystallographic study reveals that complex 1 crystallized in the system, space group. Each independent $\mathrm{Mn}(\mathrm{II})$ is located at the inversion center and coordinated by two nitrogen atoms $[\mathrm{Mn}(1)-\mathrm{N}(1)=2.2478$ (17) and $\mathrm{Mn}(1)-\mathrm{N}(3)=2.2486(18)$ ] and four carboxylate oxygen atoms [Mn-O, ranging from 2.1149 (14) $\AA$ to 2.3309 (16) $\AA$ ] to furnish an octahedral geometry. The partial deprotonated $\mathrm{H}^{2}$ btc- ligands connect the $\mathrm{Mn}$ (II) to form a one-dimensional 


\begin{tabular}{|c|c|c|c|}
\hline \multicolumn{4}{|c|}{$\begin{array}{c}\text { TABLE-1 } \\
\text { SELECTED BOND LENGTHS }(\AA) \\
\text { AND ANGLES }\left({ }^{\circ}\right) \text { FOR COMPLEX } 1\end{array}$} \\
\hline \multicolumn{4}{|c|}{ Compound $\mathbf{1}$} \\
\hline $\mathrm{Mn}(1)-\mathrm{O}(1)$ & $2.1149(14)$ & $\operatorname{Mn}(1)-\mathrm{N}(1)$ & $2.2478(17)$ \\
\hline $\operatorname{Mn}(1)-O(2)^{i}$ & $2.1343(14)$ & $\mathrm{Mn}(1)-\mathrm{O}(4)^{\mathrm{ii}}$ & $2.2930(13)$ \\
\hline $\operatorname{Mn}(1)-N(3)$ & $2.2486(18)$ & $\mathrm{Mn}(1)-\mathrm{O}(3)^{\mathrm{ii}}$ & $2.3309(16)$ \\
\hline $\mathrm{O}(1)-\mathrm{Mn}(1)-\mathrm{O}(2)^{\mathrm{I}}$ & $116.51(5)$ & $\mathrm{O}(1)-\mathrm{Mn}(1)-\mathrm{O}(4)^{\mathrm{ii}}$ & $149.26(5)$ \\
\hline $\mathrm{O}(1)-\mathrm{Mn}(1)-\mathrm{N}(3)$ & $85.60(6)$ & $\mathrm{O}(2)^{\mathrm{I}}-\mathrm{Mn}(1)-\mathrm{O}(4)^{\mathrm{ii}}$ & $93.53(5)$ \\
\hline $\mathrm{O}(2)^{\mathrm{i}}-\mathrm{Mn}(1)-\mathrm{N}(3)$ & $88.08(6)$ & $\mathrm{N}(3)-\mathrm{Mn}(1)-\mathrm{O}(4)^{\mathrm{ii}}$ & $89.25(5)$ \\
\hline $\mathrm{O}(1)-\mathrm{Mn}(1)-\mathrm{N}(1)$ & $90.94(6)$ & $\mathrm{N}(1)-\mathrm{Mn}(1)-\mathrm{O}(4)^{\mathrm{ii}}$ & $94.56(6)$ \\
\hline $\mathrm{O}(2)^{\mathrm{I}}-\mathrm{Mn}(1)-\mathrm{N}(1)$ & $92.02(6)$ & $\mathrm{O}(1)-\mathrm{Mn}(1)-\mathrm{O}(3)^{\mathrm{ii}}$ & $94.29(5)$ \\
\hline $\mathrm{N}(3)-\mathrm{Mn}(1)-\mathrm{N}(1)$ & $176.17(5)$ & $\mathrm{O}(2)^{\mathrm{I}}-\mathrm{Mn}(1)-\mathrm{O}(3)^{\mathrm{ii}}$ & $148.80(5)$ \\
\hline $\mathrm{N}(3)-\mathrm{Mn}(1)-\mathrm{O}(3)^{\mathrm{ii}}$ & $99.77(6)$ & $\mathrm{O}(4)^{\mathrm{ii}-}-\mathrm{Mn}(1)-\mathrm{O}(3)^{\mathrm{ii}}$ & $56.77(4)$ \\
\hline $\mathrm{N}(1)-\mathrm{Mn}(1)-\mathrm{O}(3)^{\mathrm{ii}}$ & $82.10(5)$ & & \\
\hline
\end{tabular}

chain. In $1 \mathrm{D}$ chain, the $\mu 2-\eta 1: \eta 1$ carboxylate group link two $\mathrm{Mn}$ (II) atoms to construct a dinuclear Mn(II) unit with the Mn...Mn distance of $4.298 \AA$. The 1D chains are further connected by bib ligands to construct a two-dimensional layer structure (Figs. 1-3).

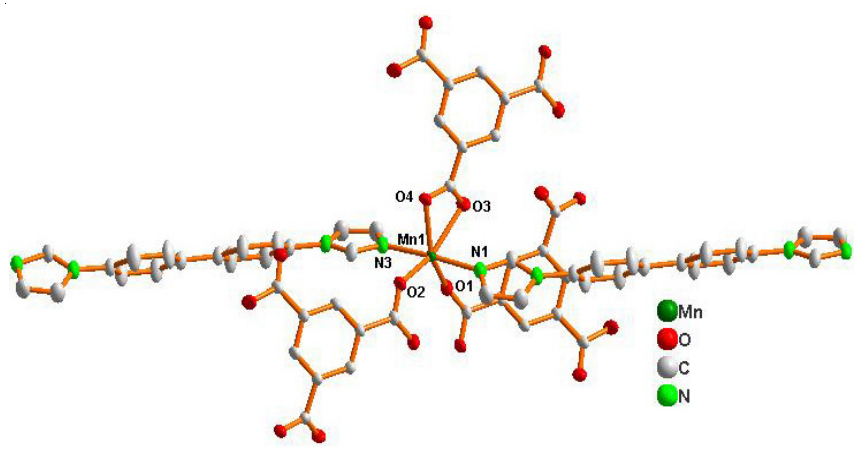

Fig. 1. Coordination environment of $\mathrm{Mn}(\mathrm{II})$ ion

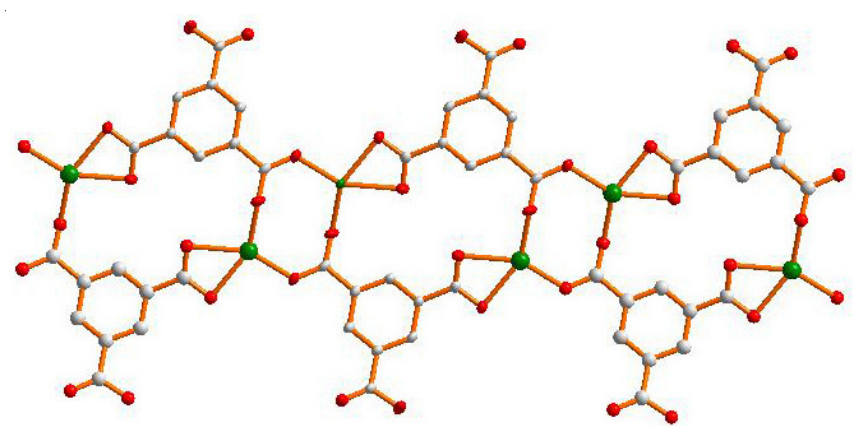

Fig. 2. 1D chain constructed by Mn(II) ions and carboxylate ligands

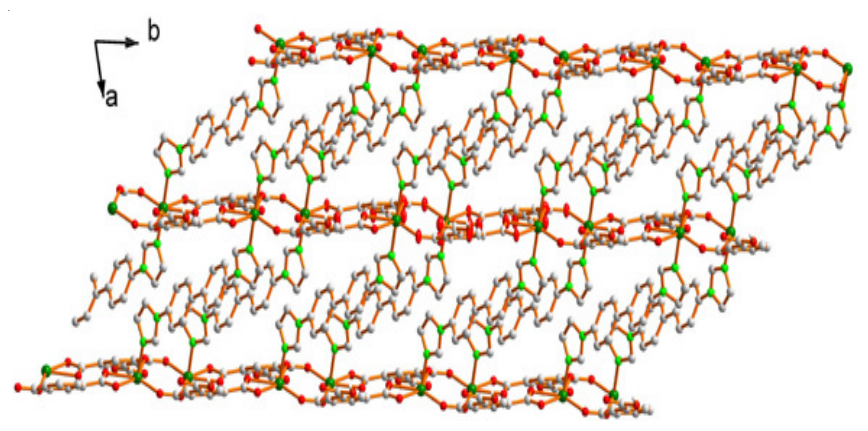

Fig. 3. 2D layer structure for complex 1

\section{ACKNOWLEDGEMENTS}

The authors gratefully acknowledged the financial support of Scientific Research Foundation of Guizhou Minzu Univeristy (GZMU-201301) and Joint Foundation between GZST and GZMU (LKM201305) and Natural Science Foundation of China (No. 21363004 and 21362005).

\section{REFERENCES}

1. P. Kanoo, G. Mostafa, R. Matsuda, S. Kitagawa and T. K. Maji, Chem. Commun., 47, 8106 (2011).

2. H. Yang, F. Wang, Y. Kang, T.H. Li and J. Zhang, Dalton Trans., 41, 2873 (2012).

3. J. Qin, C. Qin, C.-X. Wang, H. Li, L. Cui, T.-T. Li and X.-L. Wang, Cryst. Eng. Comm., 12, 4071 (2010).

4. Z.Y. Du, H.B. Xu and J.G. Mao, Inorg. Chem., 45, 9780 (2006).

5. J. Li, J. Tao, R.B. Huang and L.S. Zheng, Inorg. Chem., 51, 5988 (2012).

6. J.E.W. Cull, F. Habib and I. Korobkov, M. Murugesu and J. Scott, Inorg. Chim. Acta, 370, 98 (2011).

7. S. Zheng, T. Wu, F. Zuo, C.T. Chou, P. Feng and X. Bu, J. Am. Chem. Soc., 134, 1934 (2012).

8. H.X. Zhang, F. Wang, H. Yang, Y.X. Tan, J. Zhang and X. Bu, J. Am. Chem. Soc., 133, 11884 (2011).

9. F. Guo, X.L. Zhang, B.Y. Zhu and J.C. Qiu, J. Inorg. Organomet. Polym., 20, 38 (2010).

10. M. Du, X.J. Zhao and Y. Wang, Dalton Trans., 2065 (2004).

11. W.W. Jia, J.H. Luo and M.L. Zhu, Cryst. Growth Des., 11, 2386 (2011).

12. SAINT Software Reference Manual; Bruker AXS: Madison, WI (1998).

13. G.M. Sheldrick, SHELXTL NT, version 5.1; Program for Solution and Refinement of Crystal Structures; University of Göttingen: Göttingen, Germany (1997). 